Documentación de las Ciencias de la Información ISSN-e: $1988-2890$

https://dx.doi.org/10.5209/dcin. 77100

\title{
Catalogação de partituras musicais: reflexões e aplicações em acervos institucionais
}

\author{
Marcia Regina da Silva ${ }^{1}$; Fabiano Ferreira de Castro²; Gabriella Caroline Lemes ${ }^{3}$
}

Recibido: 30 de junio de 2021 / Aceptado: 10 de septiembre de 2021

Resumo. As partituras são registros musicais que possuem características singulares para sua produção, circulação e uso. O objetivo deste artigo é descrever e refletir sobre as principais etapas do tratamento de partituras musicais do acervo do Coral USP. Trata-se de um trabalho exploratório-descritivo e caracterizado como um relato de experiência, o qual apresenta elementos da catalogação de partituras tendo como referência o RDA, o padrão de metadados MARC, o referencial teórico acerca dos estudos a respeito da notação musical e as necessidades dos usuários identificadas no ambiente informacional. O processo de organização da particoteca seguiu um planejamento estratégico desenvolvido em três estágios: 1) diagnóstico; 2) capacitação e; 3) ações. O proceso de catalogação apresentado denota a possiblidade de criação de registros descritivos que representam as partituras enquanto documentos passíveis de recuperação em sistemas de gerenciamento bibliográfico. Conclui-se que a leitura documental e a catalogação de partituras exige do catalogador conhecimentos a respeito da estrutura do documento e da notação musical para garantir o atendimento às necessidades informacionais dos usuários, em especial no ambiente digital.

Palabras clave: Particoteca; Tratamento de partituras musicais; Sistemas de gerenciamento bibliográfico. Acervo musical.

\section{[en] Cataloguing of musical score: reflections and applications in institutional collections}

Abstract. The scores are musical records that have unique characteristics for their production, circulation and use. The objective of this article is to describe and reflect on the main stages of the treatment of musical scores of the collection of Coral USP. This is an exploratory-descriptive work and characterized as an experience report, which presents elements of score cataloging with reference to RDA, the MARC metadata standard, the theoretical reference about the studies about musical notation and the users' needs identified in the informational environment. The organization process of the music score library followed a strategic planning developed in three stages: 1) diagnosis; 2) training; and 3) actions. It was verified that the examples presented denote the possibility of creating descriptive records that represent the scores as documents that can be retrieved in bibliographic management systems. It is concluded that the reading of documents and the cataloging of scores require knowledge of the document structure and musical notation from the cataloger to ensure that the information needs of users are met, especially in the digital environment.

Keywords: Music library; Music score processing; Bibliographic management systems. Music Collection

Sumario. 1. Introdução. 2. Catalogação de partituras musicais. 3. Etapas do tratamento organizacional do acervo do Coral da USP de Ribeirão Preto. 4. Procedimentos para catalogação de partituras. 4.1. Registros descritivos de partituras do acervo do Coral/USP. 5. Considerações Finais. 6. Referências.

Cómo citar: Silva, M. R. da; Castro, F. F. de.; Lemes, G. C. (2022) Catalogação de partituras musicais: reflexões e aplicações em acervos institucionais, en Documentación de las Ciencias de la Información. 45 (1), 83-93.

\section{Introdução}

O Coral da Universidade de São Paulo (USP), localizado no campus da USP de Ribeirão Preto (São Paulo, Brasil), teve início no ano de 1983. Ao longo desse tempo constitui-se um acervo de 1500 partituras, formado com o material utilizado nos ensaios e nas apresentações, além da doação do acervo particular do maestro Sérgio Alberto de Oliveira e do acervo de documentos e partituras do Madrigal Revivis, o mais antigo grupo coral da cidade de Ribeirão Preto.

Em 2017, por meio do Edital do Programa Unificado de Bolsas de Estudos da USP, iniciou-se à realização do tratamento documental, visando à organização e à digitalização do material que compõe o acervo do Coral. Como forma de atender as necessidades imediatas dos usuários, o trabalho teve início com o estudo e processamento das partituras musicais.

\footnotetext{
Universidade de São Paulo (USP) (Brasil)

E-mail: marciaregina@usp.br

ORCID: https://orcid.org/0000-0001-5852-1026

2 Universidade de São Paulo (USP) (Brasil)

E-mail: fabianocastro@ufscar.br

ORCID: https://orcid.org/0000-0002-8712-2654

3 Universidade de São Paulo (USP) (Brasil)

E-mail: gabriellalemes@usp.br

ORCID: https://orcid.org/0000-0002-1215-2322
} 
Segundo Borges (2006, p. 4), "a partitura musical é uma forma de registro que possui características particulares em sua produção, circulação e uso e que colabora para a permanência da memória da música através do tempo e de sua projeção futura". As partituras musicais são materiais compostos por signos, geralmente não habituais para o catalogador, o que pode dificultar a qualidade da representação, em seus aspectos descritivos e temáticos.

No âmbito da organização das partituras musicais, destaca-se a necessidade de conhecimento especializado para a leitura dessa tipologia documental. Além disso, o bibliotecário deve entender as necessidades de buscas dos musicistas, coralistas e pesquisadores para a representação das partituras. Segundo Santini (2007, p. 3),

[...] percebe-se que desenvolvimentos na representação da música, na forma de notação e na forma acústica, e em bases de dados computadorizadas, sugerem a necessidade de uma "filosofia" de recuperação da informação especificamente direcionada para a busca não-textual e a eventual expansão de sistemas que dêem conta da vasta gama de informações encontradas nos documentos multimídia.

Ademais, as dificuldades tecnológicas para gestão de acervos observadas em especial nas partituras, por suas especificidades e tendo necessidade de um conhecimento prévio para serem descritas, acabam sendo tratadas de forma superficial no âmbito da Organização da Informação. Da mesma forma, os músicos e coralistas, enquanto usuários desse recurso informacional, desconhecem as formas de catalogação e organização dessa documentação, o que compromete sua recuperação.

Para Assunção (2005, p. 86, tradução nossa),

[...] A documentação musical continua a ser vista pelos bibliotecários e arquivistas como um domínio hermético de músicos e musicólogos e as técnicas documentais continuam a ser vistas pelos musicólogos como complicações inúteis dos tecnocratas.

Uma catalogação eficiente consegue representar uma música e muitos músicos. Especialistas também usam a partitura como fonte de informação e objeto de pesquisa dentro e fora do meio acadêmico, por isso, esses documentos devem ser tratados como uma fonte informacional no ambiente informacional (tradicional ou digital).

Para Caldas (2007, p.18), a catalogação deve ser vista como

[...] a representação do item, não se tratando apenas de um trabalho mecânico, sua descrição deve ir além do título e compositor levando em conta todas as particularidades de cada documento, pois cada partitura também tem seu caráter cultural e histórico que dependendo do seu arranjo pode se transformar em uma obra, a parte do autor principal, tudo isso deve ser levado em consideração ao fazer a representação.

No Brasil, é necessário muito esforço para incentivar o bibliotecário a se interessar pela área musical, pois há poucos profissionais com experiência com o tratamento do documento musical. Vale ressaltar que em países como Canadá, Estados Unidos e alguns países europeus, há uma estrutura organizada para o bibliotecário habilitado em trabalhar em ambientes informacionais musicais. Há associações como a International Association of Music Libraries (IAML), fundada em 1951, com o intuito de promover a cooperação internacional e dar suporte aos interesses dos profissionais; mestrados específicos na área em universidades renomadas como a University of British Columbia, University of California, University of Toronto etc. e; grupos de pesquisas que habitualmente produzem materiais como a Yale University Library, que divulgam guias de como catalogar músicas impressas utilizando o Resource Description and Access (RDA) ou mesmo a Biblioteca Nacional da Espanha que publicou um documento sobre a aplicação do RDA para música impressa (Servicio de Partituras, 2020).

No âmbito brasileiro, Cavalcanti e Carvalho (2011) sugeriram elementos de representação temática em partituras musicais, a fim de melhorar o processo de recuperação da informação. Caldas (2007) investigou os elementos constitutivos da partitura, tendo como objeto uma amostra de partituras manuscritas das Bachianas n.1, 2 e 4 de Heitor Villa-Lobos, os modelos de registros bibliográficos da Universidade Estadual de Campinas (UNICAMP) e da Biblioteca Nacional, levando em consideração as regras de catalogação do Anglo American Cataloging Rules (AACR) e o formato Machine Readable Cataloging (MARC). Já Faria (2009) enfatiza a necessidade em investir no tratamento de partituras, enfatizando os aspectos culturais. Padron (2019) ao propor um modelo conceitual para representação da música popular brasileira constatou que a cultura e tradições devem estar presentes no processo de representação. Além disso, Padron, Cruz e Silva (2020) concluíram que o uso de um modelo conceitual específico de domínio, pode fornecer uma formalização das percepções dos usuários sobre o conteúdo do objeto de informação.

Do ponto de vista metodológico, esse estudo caracteriza-se como uma pesquisa de natureza teórica e aplicada, que por meio do arcabouço teórico desenvolvido a partir da revisão bibliográfica sobre o processo de catalogação de partituras, buscou a reflexão, advinda dos instrumentos de descrição da Catalogação e a possibilidade de aplicação e de utilização em acervo institucional específico, a qual apresenta um relato de experiência, identificando os elementos da catalogação de partituras, tendo como referência o RDA, o padrão de metadados MARC, os estudos a respeito da notação musical e as necessidades dos usuários desse ambiente informacional. 
Embora o trabalho de Caldas (2007) seja tomado como base, esta pesquisa tem como objetivo descrever e refletir sobre as principais etapas para o tratamento do acervo de partituras do acervo do Coral USP.

Vale ressaltar que não foram desconsiderados os documentos internacionais para a representação de música impressa como o Modelo Conceitual para a Informação Bibliográfica da Federação Internacional de Associações e Instituições Bibliotecárias (IFLA/ LRM) (Riva; Le Bœuf; Žumer, 2017), no entanto, por se tratar de um relato de experiência da representação de partituras de um acervo institucional, buscou-se considerar mais as necessidades locais dos usuários para a descrição, atreladas à utilização efetiva dos padrões internacionais para a descrição de recursos.

A temática em apreço está alinhada ao campo da Comunicação Social, uma vez que a organização, o tratamento e a disponibilização de acervos restritos em ambiente Web possibilita maior visibilidade e abrangência, primando para o efetivo uso, acesso e recuperação da informação em diferentes domínios do conhecimento.

\section{Catalogação de partituras musicais}

Desde a Antiguidade, a música sempre foi a maior forma de registro e de manifestação cultural, desde apresentações para reis, deuses e comunidade. Para Candé (2001, p. 5), "a música é uma antiga sabedoria coletiva, cuja longa história se confunde com a das sociedades humanas", ou seja, a história da música também se reflete na história do mundo.

A notação musical é um sistema de escrita composta por símbolos e regras a serem executados, e é esse código que marca o registro da música a ser desempenhada pelo músico. Segundo Sadie (1994, p. 702), uma partitura é a

Figura 1. Exemplo de partitura convencional.
[...] forma de música escrita ou impressa em que pentagramas são normalmente ligados por barras de compasso alinhadas na vertical, de maneira a representar visualmente a coordenação musical. O termo, de origem italiana (partire significa "dividir"), alude à distribuição das diversas partes vocais e/ou instrumentais em diversos pentagramas (ou pautas).

As partituras são documentos que utilizam uma notação musical escrita ou impressa, para a representação de vozes e instrumentos de determinada obra, ou seja, as partituras são partes do todo que compreende as vozes e os instrumentos de execução e, assim, uma parte são as linhas dos instrumentos que serão tocadas juntos. (Sadie, 1994).

Há vários tipos de formatos de partituras, tais como: partitura completa, parte, piano-condutor, partitura abreviada, partitura de coro, partitura de estúdio (reduzida), partitura vocal, partitura de script, redução para piano, partitura cantoral, partitura condensada, arranjos, adaptações e transcrições e partitura de mesa (Bordonau, 2011). Algumas dessas são convencionais e fáceis de identificar por conter um padrão em sua estrutura, outras são mais complexas. Porém, é necessário entender que uma partitura pode ir além de sua convencionalidade e o catalogador deve ser capaz de interpretá-la e catalogá-la de forma mais eficiente. De acordo com Bordonau (2011, p. 10 , tradução nossa) "[...] é obrigatório para o catalogador expandir a lista de formatos, se o documento em questão não couber em nenhum deles".

De forma geral, todas partituras são nomeadas de acordo com a sua tipologia, um dos principais fatores de recuperação para usuários de música. Na Figura 1 apresenta-se um exemplo de partitura convencional. Na Figura 2 apresenta-se um exemplo de partitura não convencional que possui uma estrutura diferente, exigindo ainda mais familiaridade para a compreensão de profissionais que estão fora da área musical.

Figura 2 - Exemplo de Partitura não convencional.
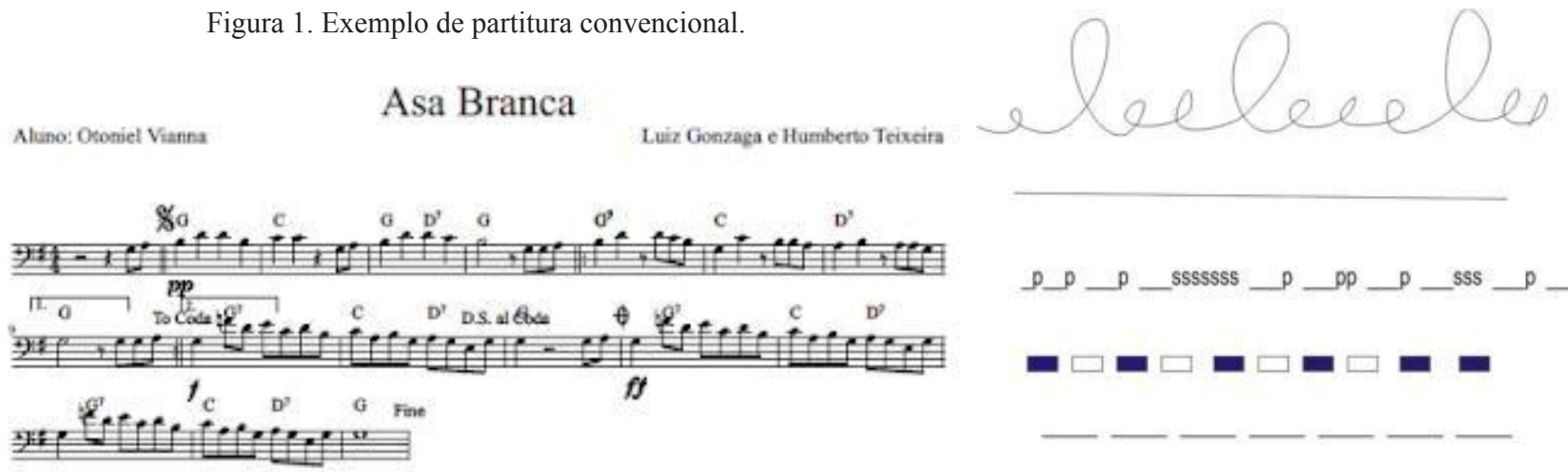

Fonte: Parte de uma partitura da Música Asa Branca (Acervo Coral USP)

Ballesté e Almeida (2019) sugerem a organização de partituras usando dois níveis conceituais: a obra e o documento musicográfico. Utilizando como objeto de estudo o acervo de um importante compositor brasileiro de orquestra, Radamés Gnatalli, os autores buscan diferenciar uma "obra" de um "documento musicográfico", entendendo "obra" como uma criação artística, a composição musical. Já "documento 
musicográfico" foi caracterizado pela notação musical de uma obra, como coletâneas, partes, entre outros. Seguindo dessa forma o modelo conceitual dos Requisitos Funcionais para Descrição Bibliográfica (FRBR) e, por sua vez, as regras do RDA.

Lisena e Troncy (2017, p. 1, tradução nossa) reforçam alguns aspectos da catalogação de músicas impressas:

[...] os metadados da música podem ser muito complexos. Descrever uma obra-prima clássica em todas as suas formas (composição, partitura, várias publicações, performance, gravação, trabalhos derivados etc.) é uma atividade complexa.

Como observado na literatura, a catalogação de partituras exige maior familiaridade do bibliotecário com o documento e com as necessidades dos usuários. Neste sentido, serão apresentadas na próxima seção as etapas do tratamento organizacional do acervo do Coral da USP, enfantizando alguns elementos considerados importantes nessa tarefa.

\section{Etapas do tratamento organizacional do acervo do Coral da USP de Ribeirão Preto}

A organização do acervo de partituras do Coral da USP seguiu um planejamento estratégico desenvolvido em três estágios: 1 ) diagnóstico; 2) capacitação e; 3 ) ações.

No estágio 1 - Diagnóstico - buscou-se levantar e organizar informações para a tomada de decisões. Este estágio foi desenvolvido em três etapas, a saber:

$1^{\text {a }}$. Etapa - entrevista com o gestor do acervo, que é o maestro do Coral, com o intuito de entender a formação histórica do acervo;

$2^{\mathrm{a}}$. Etapa - diagnóstico dos aspectos físicos do acervo (armazenamento e mobiliário). A Particoteca, como é chamado o acervo de partituras do Coral da USP, estava armazenada em um armário de madeira, dentro de um dos quartos do imóvel. A casa 3 , onde está instalada o Coral da USP de Ribeirão Preto, é uma casa doméstica antiga de pisos e móveis amadeirados. Observou-se no local forte odor de papel decomposto, falta de ventilação e umidade na parede. Todos esses fatores são determinantes para colocar em risco todo o acervo. Foram tomadas providências a respeito do acondionamento desses materiais, que não serão abordadas neste artigo;

$3^{\mathrm{a}}$. Etapa - diagnóstico da organização e acesso ao acervo. As partituras encontravam-se organizadas alfabeticamente por sobrenome de autor e registradas em uma planilha de Excel. A descrição de cada uma das partituras não seguia os preceitos da catalogação, mas continha informações valiosas acerca do histórico musical de cada documento, por exemplo: o estilo, a formação e a coletânea. Esse registro foi realizado por coralistas, estagiários e pelo próprio maestro no decorrer do tempo, por isso, alguns estavam mais completos do que outros. A planilha de Excel não era utilizada para a localização da partitura, pois não havia nenhum critério de ordem de localização, mas para controle do conteúdo;

$4^{\text {a }}$. Etapa - Estudo de Usuário. O estudo de usuário buscou levantar as necessidades dos coralistas e músicos que frequentam a Particoteca e compreender a demanda para o estabelecimento de critérios de padronização, de acordo com o comportamento de busca do usuário. Para esse estudo optou-se pelo método da observação e entrevistas com os usuários da Particoteca. As entrevistas consistiram nas seguintes questões: Quais são seus interesses com o acervo de partituras? Como você faz a busca? Que informações você precisa para buscar as partituras fisicamente? Você considera eficiente o sistema de busca e recuperação de partituras nesse acervo? Você sempre encontra os documentos procurados? As respostas foram bastante esclarecedoras e refletiram a necessidade de um acervo melhor organizado. Sem uma sistemática de busca, o método utilizado pelos usuários consistia na localização da partitura nas pastas por autor. Os principais elementos de busca citados pelos entrevistados foram o título da partitura, o autor, o arranjo, a letra, a formação, o estilo e a série. Alguns desses itens como a formação e o estilo, nem sempre são expostos em uma partitura. Outro ponto é que apesar de muitas partituras terem a estrutura parecida, algumas podem ter sido registradas à mão ou até mesmo algum arranjo pode ter sido incorporado de última hora, o que revela o caráter sentimental e histórico das partituras e reafirma a importância e o cuidado de se trabalhar com esses documentos.

Após o levantamento de informações no Estágio 1, avançou-se para o desenvolvimento do Estágio 2, referente à capacitação. A capacitação envolveu a realização de um curso, intitulado "Musicando: curso de teoria e percepção musical com ênfase em canto coral" oferecido pelo Coral da USP. O curso abordou uma introdução teórica de leitura de partituras, reconhecimento de um pentagrama, identificação de notas e compassos.

No Estágio 3 - Ações - refere-se à organização física do acervo, definição do software de gerenciamento de biblioteca e descrição das partituras.

O Coral da USP é uma entidade sem fins lucrativos, não possui verba direta para aquisição ou para a assinatura de um software. A opção, após algumas avaliações foi a utilização de um software livre, o Biblivre. O projeto do Biblivre foi patrocinado pela IBM-Brasil em parceria com o Itaú Cultural. O Biblivre contém o módulo para catalogação de partituras e, ainda que os campos disponíveis para a descrição desses documentos não espelham todas necessidades dos usuários, o software utiliza um sistema operacional que é de fácil manipulação para os bibliotecários. Outra funcionalidade a destacar é a possibilidade de anexar um arquivo em cada item catalogado. No caso do Coral, optou-se por anexar a cópia digitalizada da partitura com domínio público nos registros corres- 
pondentes. Essa opção permite que os usuários não precisem utilizar necessariamente grande parte das partituras físicas para a realização de seus trabalhos.

\section{Procedimentos para catalogação de partituras}

Uma partitura pode ser estruturada de várias formas, mas informações fixas como o autor e o título são fundamentais para a compreensão do conteúdo do documento. Algumas informações como a formação, o estilo e as vozes nem sempre são evidentes. Nestes casos, é necessário a leitura especializada mais aprofundada.

Há duas formas de análise de uma obra: a especializada e a reflexiva. Esse modo de estruturar um recurso informacional é mais utilizada em tratamento de informações em museus. No entanto, se encaixa em harmonia com as partituras musicais, por ser um documento repleto de representações históricas, culturais e pessoais (Ceravolo, 2000).

A finalidade da análise especializada é a conexão entre registros, as referências cruzadas e sua recuperação. Trata-se, pois, da análise das informações perceptíveis ao catalogador, como a composição, a técnica e a morfologia (forma, dimensão, cores, superfície). $\mathrm{Na}$ análise reflexiva o catalogador deve recorrer a outras fontes que não o recurso para sua identificação, como o contexto em que ele existiu, sua funcionalidade, significado e história. Para Ceravolo (2000, p. 242), a análise reflexiva "debruça-se sobre a importância do objeto como documento e suporte de informações significativas para as pesquisas científicas".

A catalogação de partituras do Coral da USP foi pensado primeiramente na análise especializada, para comprender seu gerenciamento e organização e depois na análise reflexiva, já que incorporou elementos importantes em sua composição que não estavam evidentes.

O software Biblivre utiliza o padrão de metadados MARC21 para a catalogação de recursos bibliográficos. Os campos do MARC21 para a catalogação de partituras incluem 61 etiquetas. O critério de escolha dessas etiquetas considerou as orientações do RDA para a catalogação de partituras, mas buscou atender às necessidades dos usuários apontadas no estudo. Desse modo, o sistema foi modelado a partir da definição dos metadados considerados mais importantes para a descrição das partituras do Coral USP. Segue observações sobre algumas etiquetas do MARC 21.

\section{Etiqueta 000}

Esse campo é específico para à organização física do documento. A escolha da classificação foi baseada no tamanho e no suporte do ambiente informacional. É importante observar se a partitura é uma parte de instrumento, um arranjo, parte da obra original ou se é documento único. Cada arranjo foi considerado como um documento diferente de um original, respeitando sua criação, sendo catalogado como um documento único. Neste caso, foi feita uma relação com a partitura original, descrita no campo de assunto. As cópias idênticas foram usadas como itens e não tiveram um número de localização específico.

\section{Etiqueta 100}

Esse campo contempla a descrição do criador da obra. Considerou-se o criador como entrada principal da obra e como entrada secundária o arranjador, o tradutor e outros participantes. Para Ribeiro (2006, p. 5), "pontos de acesso para música podem ser pessoas ou entidades, como compositores, autores de arranjos, transcrições, adaptações etc, ou pelo título". Quando o criador era desconhecido, a entrada principal foi realizada pelo título e a entrada secundária para o arranjador. Não se coloca siglas para arranjo ou organização, pois pode dificultar na recuperação por nome de autor.

\section{Etiqueta 245}

O título deve ser colocado na sua forma mais conhecida, respeitando o que estiver na partitura. Traduções e outras variações de títulos foram descritas como entrada secundária. No caso de uma coletânea com várias músicas, optou-se por colocar o título da coletânea na etiqueta 245 e as músicas contidas na obra em nota de conteúdo.

\section{Etiqueta 382}

Este campo é muito utilizado para música impressa. $\mathrm{O}$ termo SATB, foi utilizado para descrever as quatro vozes Soprano, Alto, Tenor e Baixo. O SATB é reconhecido internacionalmente com essa sigla, em muitas partituras ela já é informada. Em alguns partituras não há nenhuma informação sobre os tipos de vozes, assim é necessário observar alguns fatores importantes, como o número de pautas dentro de um pentagrama. Se houver quatro pautas, então se deduz que são quatro tipos de vozes mistas (SATB).

Quando uma pauta está com apenas um ou dois tipos de vozes e em baixo outros, é comum separá-los para mostrar que eles cantam juntos em outro tempo, como no exemplo de Ode à Alegria, de Beethoven, que o Soprano e Contralto cantam juntos, separados do Tenor e Baixo, que também cantam juntos. No Biblivre há interferência na recuperação ao colocar o SATB separado. Justamente por essa razão, mesmo quando os tipos de vozes estão separados, optou-se por coloca-los juntos para apenas mostrar quais são as vozes que contém a partitura.

É importante se atentar ao catalogar partituras quando houver "apenas vozes masculinas" ou "apenas vozes femininas". Pode-se confundir, por exemplo, quando um pentagrama houver quatro pautas e não estiver informado se é apenas para vozes mas- 
culinas/femininas, pois o soprano e o contralto são vozes femininas e o baixo e o tenor masculinas. Se houver quatro pautas escrito "apenas vozes masculinas", então não podemos utilizar os termos SATB e sim TTBB ou outro tipo de formação com apenas vozes masculinas. $\mathrm{O}$ mesmo acontece com as vozes femininas (SSAA). Se houver "Coro Misto" pode-se colocar SATB direto. Colocar Solo ou Voz quando é apenas uma pessoa cantando.

O piano na formação, se constata sempre que o pentagrama fica sozinho dentro da pauta, isso também serve para outros instrumentos. Nota-se, também, que quando há instrumentação, não há a letra da música acompanhado das notas. Em algumas partituras, a instrumentação vem com vários instrumentos, como é o caso de uma partitura de orquestra e música de câmera. Se a partitura não informar qual é o instrumento, não há como saber, apenas com um nível maior de conhecimento de música para entender os tons de cada som específico.

Outro fator importante é que na instrumentação é comum citar Quarteto de Cordas (dois Violinos, o Violoncelo e a Viola) e Quinteto de Sopro (Fagote, Trompa, Clarinete, Oboé e Flauta). Nesses casos, deve-se colocar cada instrumento na formação para facilitar o acesso. Normalmente, em uma Orquestra ou Música de Câmara há mais de um mesmo instrumento e eles sempre informam como Violino I e Violino II; catalogam-se as partes diferentes da mesma obra, além de informar se contém letra e cifra.

\section{Etiqueta 500}

Este campo é reservado para a inclusão de informações adicionais que possam contribuir com à identificação do registro pelo usuário. $\mathrm{Na}$ catalogação de partituras o campo 500 é bastante utilizado.

\section{Etiqueta 650}

A etiqueta 650 "Assunto Tópico" no Biblivre permite formar uma estruturação baseada em um vocabulário controlado de música. Este campo permite adicionar subcampos de acordo com a terminologia. O campo
650 permite construir padrões de entradas que servirão para melhor definir a variedade de assuntos do documento. Ao explorar essa função podemos adicionar o tipo de voz, o estilo musical, o instrumento etc.

O maestro, os coralistas e os músicos contribuíram no processo de indexação. Por essa razão, optou-se por adotar também alguns termos empregados por esses profissionais no campo 650. Nesse campo é desejável descrever tudo o que for favorável para a recuperação, mas sempre mantendo a padronização, como o estilo de música (Jazz, MB, Negro Spiritual, Folclore etc.) ou o período (como Barroco, Renascença, Clássico ou Contemporâneo). Também é possível considerar assuntos-chave de recuperação como, Natal, Disney e Coro Infantil.

\section{Etiqueta 700}

Entrada secundária para responsáveis e títulos da obra que não se figurou como entrada principal.

\section{Etiqueta 730}

Ponto de acesso de uma obra relacionada do acervo.

\section{Etiqueta 856}

Endereço eletrônico do item.

\subsection{Registros descritivos de partituras do acervo do Coral/USP}

O primeiro exemplo descrito é a partitura Ode à Alegria de L. Van Beethoven, conforme Figura 3. É necessário observar se a mesma obra faz parte de uma partitura completa ou uma parte de partitura. A partitura completa é muito usada para ver a obra ao todo com todos os instrumentos, vozes, letra etc. Como no caso do exemplo de Ode à alegria. A parte de uma partitura é quando se retira a pauta do pentagrama que o músico irá utilizar, desconsiderando os outros. Em uma orquestra, por exemplo, se retira a parte do instrumento, no caso de um coral se retira o tipo de voz etc. 
Figura 3. Ode à Alegria de L. Van Beethoven

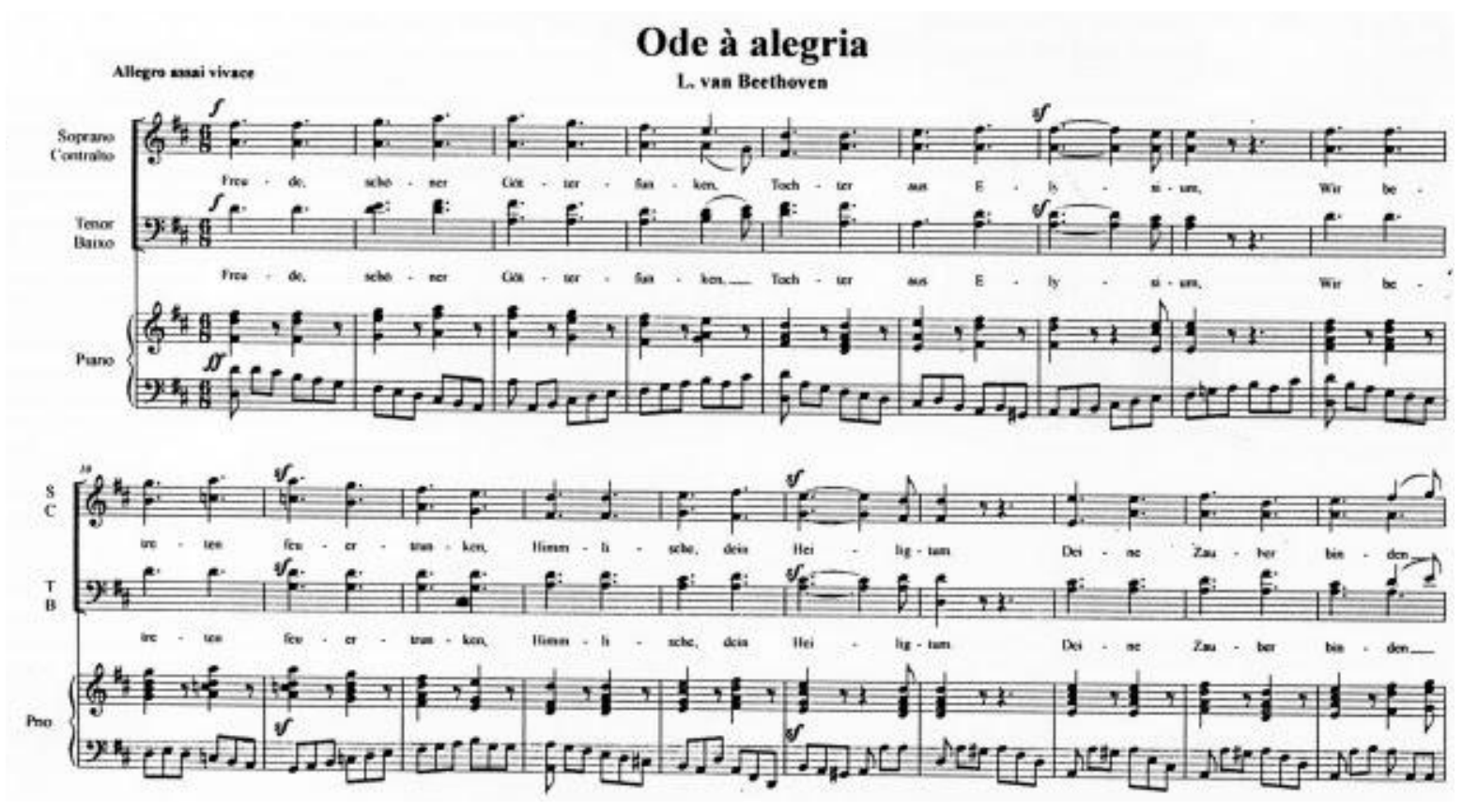

Fonte: Acervo do Coral USP

Nesse exemplo demonstra-se uma das formas de leitura de uma partitura, que contém as informações necessárias para a catalogação como o autor, o título, as vozes e os instrumentos (formação). Trata-se da obra musical Ode à alegria, música do último movimento da $9^{\circ}$ Sinfonia de Beethoven. Dependendo do tamanho do acervo musical é importante adicionar essas informações para melhorar a qualidade do registro. Outras partituras de Ode à alegria, nas línguas inglesa e alemã foram encontradas no acervo do Coral, por isso optou-se por colocar como título uniforme as formas variantes do título.

Figura 4. Registro catalográfico da obra musical Ode à alegria em MARC 21 e RDA.

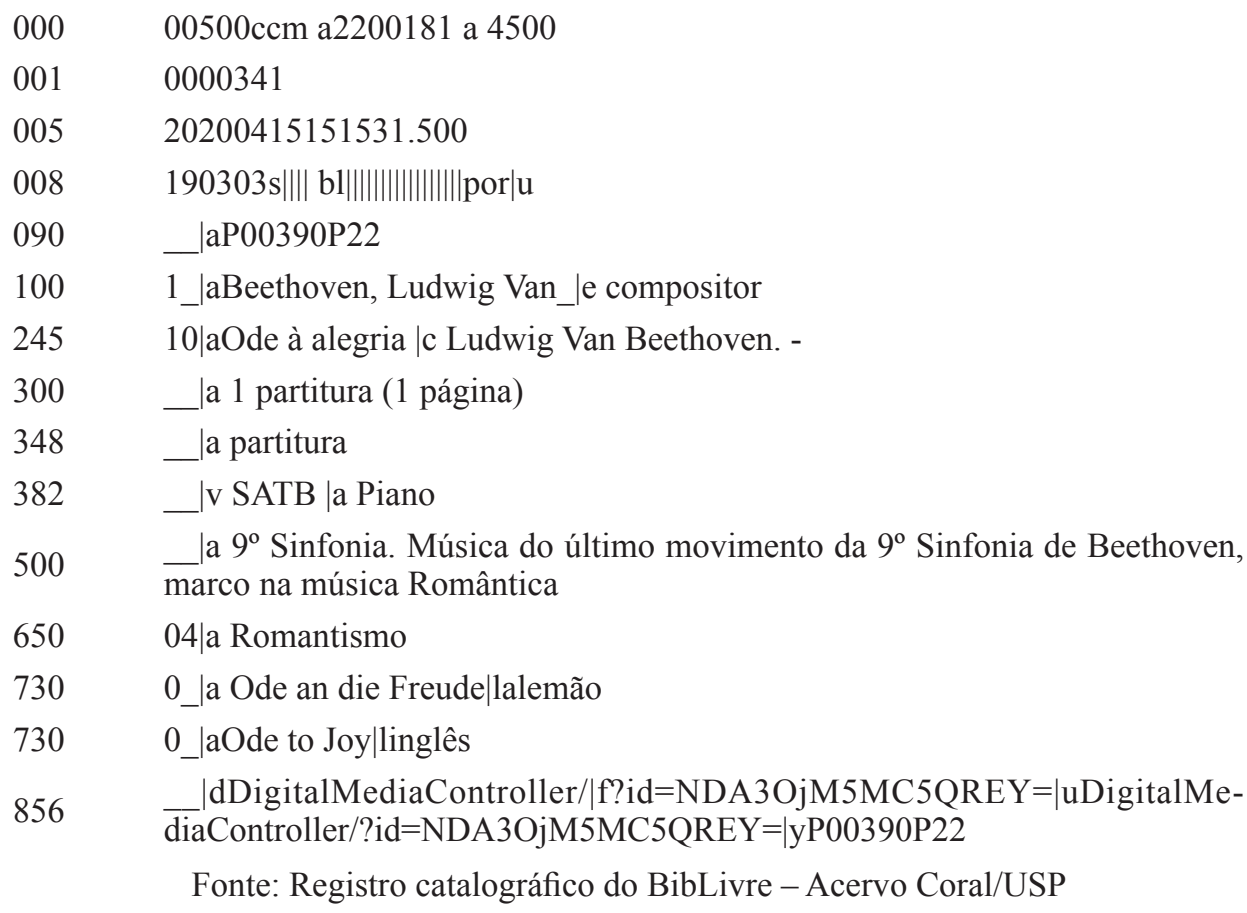

O próximo exemplo descrito é a partitura de orquestra de Johann Sebastian Bach, conforme Figura 5. 
Figura 5 - Partitura de orquestra de Johann Sebastian Bach

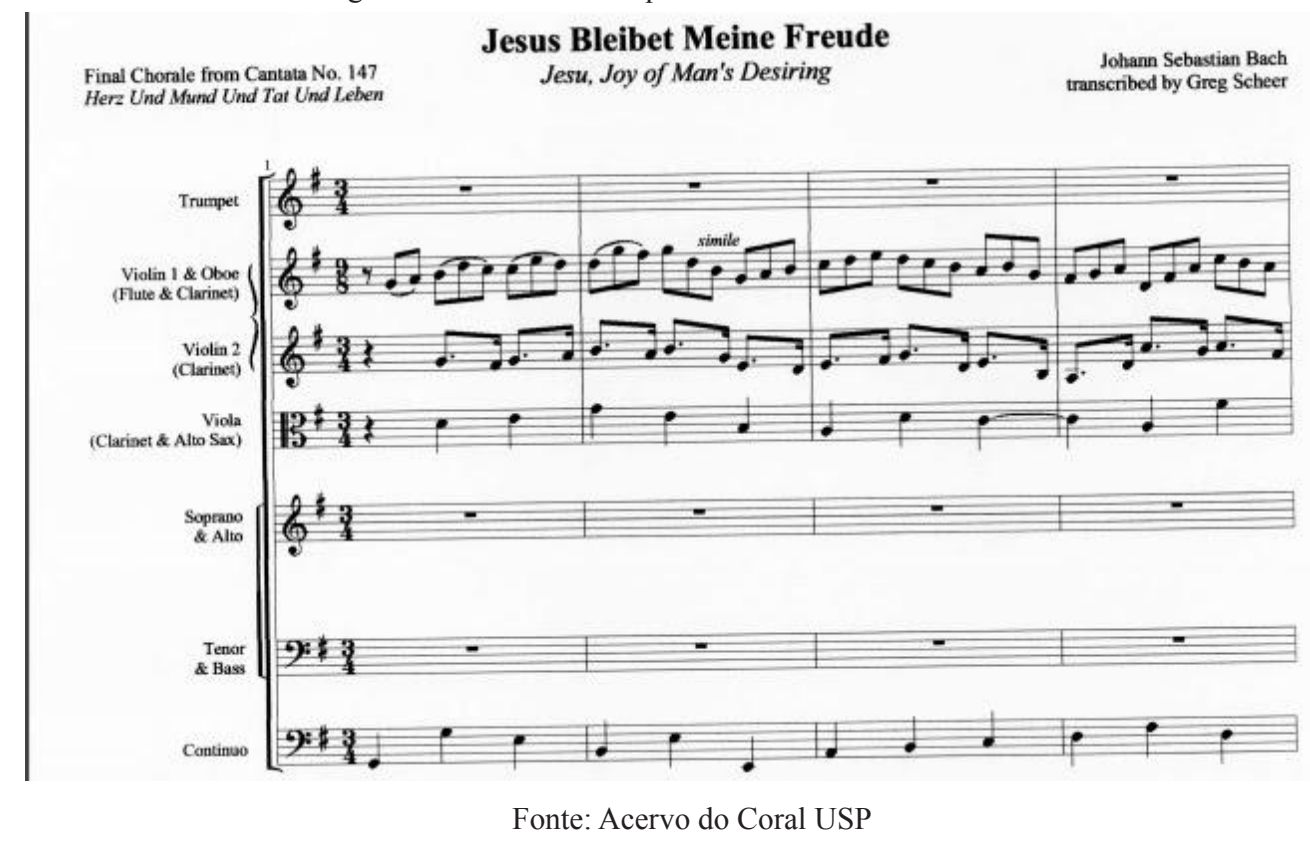

Nessa partitura de Orquestra foram consideradas todas as informações da partitura e adicionados alguns complementos relevantes para facilitar a busca,

como variações das línguas do título, nesse caso em alemão e em inglês.

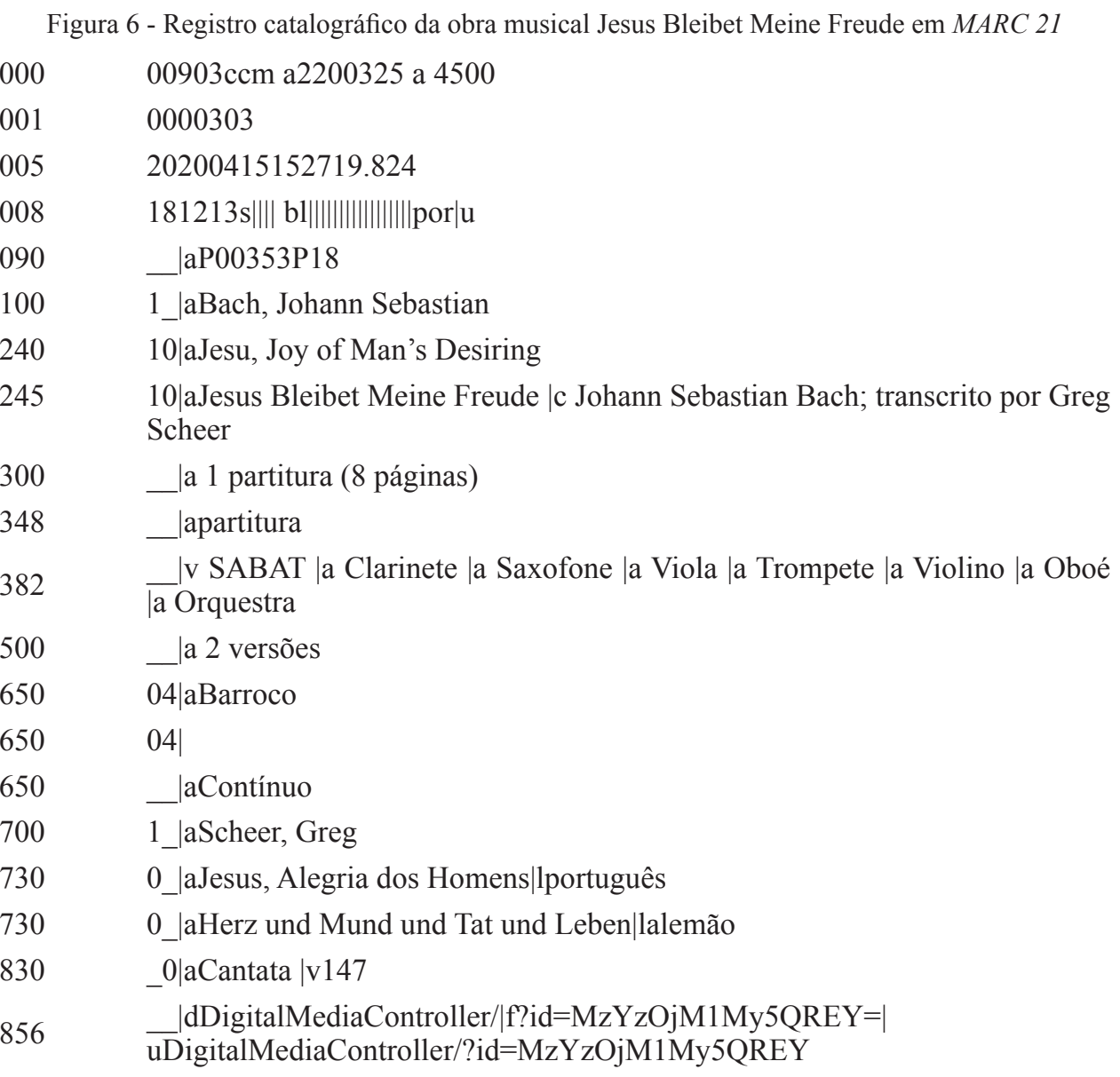

No terceiro exemplo apresenta-se a partitura de uma coletânea composta por várias obras de Lamartine Babo, conforme Figura 7. 
Figura 7 - Partitura da coletânea Carnaval II
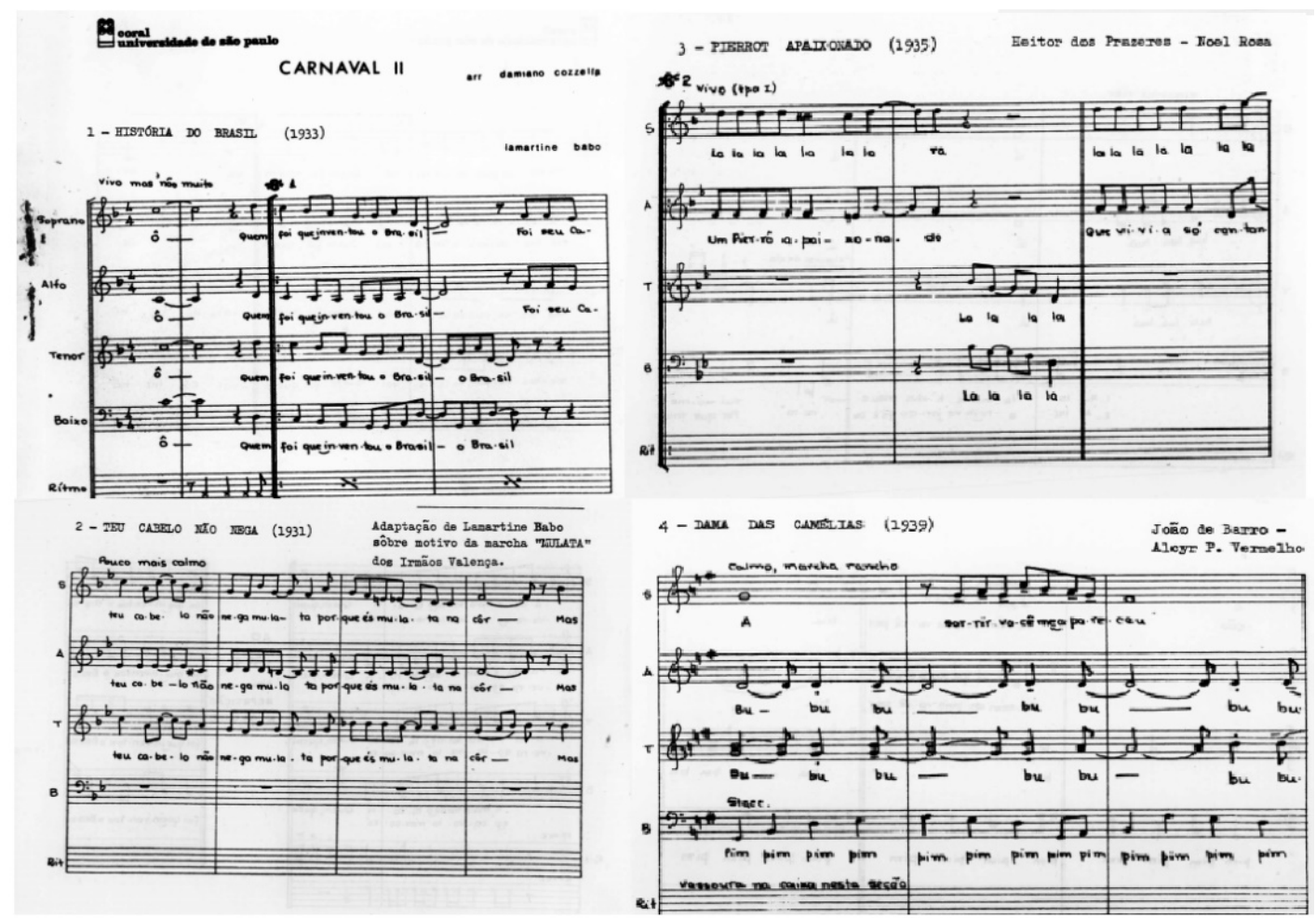

Fonte: Acervo do Coral USP

Nessa coletânea adaptada de Lamartine Babo há várias músicas de autores diferentes, e por isso foram considerados como autores secundários da obra. Em notasforam colocadas todas as obras que compõem a coletânea. Apresenta-se na Figura 8 a descrição dessa coletânea.

Figura 8 - Registro catalográfico da coletânea Carnaval II

$000 \quad 00746 \mathrm{ccm}$ a2200217 a 4500

$001 \quad 0000283$

$005 \quad 20190624173927.449$

$008 \quad 181204 \mathrm{~s}||||$ b1||||||||||||||||||por|u

$090 \_$_aP00334P17

1001 1_aBabo, Lamartine |e compositor

$24510|a C a r n a v a l ~ I I ~| c$ Lamartine Babo; músicas de Heitor Prazeres, Damiano Cozzella, Alberto Ribeiro, João de Barro, Alcyr P. Vermelho e Noel Rosa.

$300 \_$_a 1 partitura (10 páginas)

$348 \_$_a partitura

$382 \_$_vSATB

$505 \quad$ a 1. História do Brasil; 2. Teu Cabelo Não Nega; 3. Pierrot Apaixonado; 4. Dama Das Camélias; 5. Yes, Nós Temos Bananas)

$650 \_$_aRitmo

$700 \quad 1$ aPrazeres, Heitor

700 1_a Cozzella, Damiano

700 1_aRibeiro, Alberto

700 1_aBarro, João de

$700 \quad 1 \_\mid$aVermelho, Alcyr P.

$700 \quad 1 \_\mid a R o s a$, Noel

$856 \_$dDigitalMediaController/|f?id=MzQ00jMzNC5QREY=| uDigitalMediaController/?id=MzQ0OjMzNC5QREY 
Nos exemplos apresentados não foi comentado o preenchimento dos indicadores, alguns criados automaticamente pela escolha do tipo de documento, outros informados pelo catalogador, de acordo com as orientações do campo a ser descrito.

\section{Considerações Finais}

Esse estudo buscou a reflexão sobre a catalogação de partituras musicais, as quais apresentam características e especificidades próprias, requerendo uma maior atenção e competência para o tratamento desse recurso informacional. Para tanto, buscou-se na literatura científica elementos teórico-metodológicos que pudessem subsidiar a discussão e, por meio de um relato de experiência, apresentar o tratamento de partituras musicais do acervo do Coral USP, na cidade de Ribeirão Preto, no estado de São Paulo, no Brasil.

Observou-se a necessidade da realização de pesquisa individual das partituras musicais para a extração de atributos descritivos específicos. Esse processo certamente contribui para que o catalogador se familiarize com as características desse recurso informacional, tornando a descrição cada vez mais rica e completa, primando para o repasse de maior possibilidade de pontos de acesso aos recursos disponíveis nos catálogos institucionais.

Outro ponto a destacar para catalogadores iniciantes nesse domínio é a necessidade de buscar conhecimentos especializados, como a realização de cursos ou treinamentos sobre a estrutura das partituras e a leitura de notações musicais, os quais devem estar respaldados na capacitação e na atualização dos instrumentos de descrição utilizados no processo de catalogação, por exemplo, o RDA e de acordo com as mudanças ocorridas com o contexto tecnológico vigente, caracterizado pela proposta de unificação dos modelos conceituais, como o IFLA LRM.

Ressalta-se que esse estudo, além de descrever as principais etapas para o tratamento do acervo de partituras do acervo do Coral USP, apresenta-se como um ponto de partida para a reflexão cuidadosa da catalogação de partituras musicais, contribuindo com elementos indispensáveis sobre a importância da interação do bibliotecário catalogador com o domínio musical, para a descrição e a representação de partituras musicais que atendam às necessidades dos principais interessados em sua recuperação: os músicos e os profissionais da música.

\section{Referências}

Assunção, M. C. R. da S. (2005). Conservación, gestión y valoración del patrimonio musical regional. Anais da I Jornadas sobre Patrimonio Bibliografico en Castilla - La Mancha. Consejería de Cultura de Castilla La Mancha.

Ballesté, A. O., \& Almeida, A. (2019). Organização do acervo de partituras de radamés gnattali usando dois níveis conceituais: obra e documento musicográfico. Anais do 20 Encontro Nacional de Pesquisa em Ciência da Informação. Florianópolis. http://hdl.handle.net/20.500.11959/brapci/123440.

Bordonau, E. B. (2011). Documentación musical: cuaderno de trabajo. Facultad de Ciencias de la Documentación, Universidad Complutense de Madrid.

Borges, J. (2006). Partitura musical: um instrumento de investigação em história e educação. Anais do 16 Congresso Nacional de Pesquisa de Pósgraduação em Música. Brasília: ANPPOM. http://www.anppom.com.br/anais/anaiscongresso_anppom_2006/CDROM/COM /01_Com_EdMus/sessao02/01COM_EdMus_0202-239.pdf.

Caldas, S.E.S. de (2007). Elementos necessários à representação descritiva de partituras: um estudo com as Bachianas Brasileiras n.1, 2 e 4 de Heitor Villa - Lobos. Pontifícia Universidade Católica de Campinas.

Cavalcanti, H. C., \& Carvalho, M. A. (2011). A informação na música impressa: elementos para análise documental e representação de conteúdos. Revista Digital de Biblioteconomia \& Ciência da Informação, 9(1), p. 132-151. https:// brapci.inf.br/index.php/res/v/40102

Candé, R. de. (2001). História universal da música. 2. Martins Fontes.

Ceravolo, S. M., \& Tálamo, M.F.G.M. (2000). Tratamento e organização de informações documentárias em museus. Revista do Museu de Arqueologia e Etnologia, 10, p. 241-253. https://www.revistas.usp.br/revmae/article/view/109390

Faria, M. M. de (2009). O tratamento documental dos arquivos musicais e a busca de práticas comuns no tratamento da música brasileira para orquestra. Opus, 15(1), p. 85-90. jun. http://www.anppom.com.br/revista/index.php/opus/ article/view/267.

Lisena, P., \& Troncy, R. (2017). Doing reusable musical data (DOREMUS). Proceedings do K-CAP2017 Workshops and Tutorials. http://ceur-ws.org/Vol-2065/paper14.pdf/

Padron, M. F. (2019). Uma proposta de modelo conceitual para representação da música popular brasileira. Dissertação (Mestrado), Pós-graduação em Ciência da Informação, Faculdade de Ciência da Informação, Universidade de Brasília, Brasília. https://repositorio.unb.br/handle/10482/ 35807

Padron, M. F., Cruz, F. W., \& Silva, J. R. F. Extending the IFLA Library Reference Model for a Brazilian popular music digital library. International Journal on Digital Libraries, 21, p. 289-306. 
Riva, P., Le Boeuf, P., \& Žumer, M. (2017). IFLA Library Reference Model: a conceptual model for bibliographic information. Final report, as amended and corrected through december 2017, IFLA. https://www.ifla.org/files/assets/ cataloguing/frbr-lrm/iflalrm-august-2017_rev201712.pdf

Sadie, S. (Ed.) (1994). Dicionário Grove de música: edição concisa. Rio de Janeiro: Jorge Zahar Ed. http://www.ala.org/ alcts/confevents/webinars/041614

Santini, R. M., \& Souza, R. F. de S. (2007). Recuperação da informação de música e a ciência da informação: tendências e desafios de pesquisa. Anais do 7 Encontro Nacional de Pesquisa em Ciência da Informação. http://www.enancib. ppgci.ufba.br/artigos/GT2.

Servicio de Partituras. Departamento de Música y Audiovisuales (2020). Perfil de aplicación de RDA para música notada en la Biblioteca Nacional de España. http://www.bne.es/export/sites/BNWEB1/webdocs/Inicio/Perfiles/Bibliotecarios/RDA/perfil_rda_partituras.pdf. 